\title{
DIGITAL ETHNICITY - EMERGING PROFILES
}

\author{
Nan B. Adams and Thomas A. DeVaney \\ Southeastern Louisiana University, USA
}

\begin{abstract}
Digital Ethnicity is a model developed to provide an organized method to define human interaction with digital communication technologies and the result of these interactions on cultural development. The ultimate goal for the development of Digital Ethnicity as a concept is to describe those aspects of digital ethnicity that influence society. These digital ethnic aspects are intended to guide thinking and provide insight into the social and educational needs of rapidly changing societal groupings by providing guidance for leaders and educators to address the biological, social and cognitive changes brought about by pervasive use of digital communication technologies. Digital Profiles have emerged by certain demographic characteristics - most notably, age and gender. This paper discusses these emerging profiles.
\end{abstract}

\section{KEYWORDS}

Social Aspects of Technological Change, Digital Communication, Learning Theory, Ethnicity

\section{INTRODUCTION}

Much of current literature focuses on various effects the rapid and pervasive emergence of social media has on our everyday lives. Ethnographies, how to interact with the Internet of Things (IoT) and casting the future as no longer human seem to dominate the discussion. This de facto conversation is interesting, but often misses cohesion and reflects an observation or response to some undefined phenomenon rather than an attempt to organize these effects to guide action. The reality is that the influence of these digital communication technologies referred to as social media is changing human actions and beliefs. The construction of our social reality is in flux. For over a decade, the majority of the world's population 'text' rather than 'talk'; couples fall in love online and meet after the fact; gender identity is becoming a choice made not by biology but by a screen name or the physical appearance of an avatar. Pew Research Center (2017) reported 2/3rds of Americans get at least some of their news from social media - and for the first time, $55 \%$ of these Americans are ages 50 or older. For the under 50 demographic, $74 \%$ of Americans of all races get news on social media sites. Facebook is the most commonly cited social media site, but Twitter, YouTube and Snapchat are sites on the rise. As a result of this phenomenal use of social media, social groups are formed in these virtual spaces that provide new kinds of common identity to previously disparate individuals. The Digital Ethnicity Model has yielded Digital Profiles based on certain demographic characteristics. These emerging Digital Profiles may provide insight into understanding into how society is changing under the influence of digital tools.

\section{BODY OF PAPER}

Akin (2016) wrote about the 'cyber effect' and discussed 'when humans and technology collide'. She discussed that "some changes have occurred so quickly that it has become difficult to tell the difference between passing trends, still evolving behavior, and somethings that's already become an acceptable social norm (p.4)." She observed the significant need to study the cyber effect along with the challenges this poses for systematic academic study of this phenomenon and terms this an accelerated form of socialization. As the concept of Digital Ethnicity is explored, differences in gender use of computers and social media are of interest to development of Digital Ethnicity Profiles. 
In a meta-analysis of 71 studies utilizing 644 different measures, Kay concluded that "actual computer behaviour has been studied far less than frequency of computer use, yet it is specific behaviour that can help uncover clues and nuances with respect to gender differences" (2008, p.19). In 2015, different computer activities were found to be used by different genders, with males performing more gaming and surfing the net, and females more email and communication-type activities (Fairlie, 2015).

The rapid increase in use of social media over the past 15 years reveals similar complexities. The difference between genders consistently reveals that females are more engaged with social media than males. According to Pew Research (2019), in 2010, 39\% of males were engaged with at least one social media site, whereas $46 \%$ of females were engaged. This trend has held. The same longitudinal study by Pew indicates that in $2019,65 \%$ of males are engaged regularly on at least one social media site, compared to $78 \%$ of females.

Differences of computer and social media use by Age have also been documented. According to the Pew Research Center surveys of social media use, there are substantial differences in social media use by age. Some $88 \%$ of 18 - to 29 -year-olds indicate that they use any form of social media. That share falls to $78 \%$ among those ages 30 to 49, to $64 \%$ among those ages 50 to 64 and to $37 \%$ among Americans 65 and older. Statista (2019) publishes similar statistics, listing 100\% of 18-19 year olds having internet access. That number falls to $97 \%$ of $30-49$ year-olds, then $88 \%$ of $50-64$ year-olds, and reveals that $73 \%$ of those over the age of 65 have internet access.

The question arises - how does increased use of computers and social media that has developed a level of seamless interconnectedness influence the development of our society - more specifically, how does it impact how people belong to that society? Restated - How does interaction with computers and other digital communication technologies, commonly called social media, influence ethnicity? What ethnic profiles may be developed using the Digital Ethnicity Model?

\subsection{Aspects of Ethnicity - The Underlying Theory and Working Model}

Longstreet (1978) developed a functional model for the 5 aspects that may be used to describe her concept of ethnicity. These aspects are (a) verbal communication, (b) nonverbal communication, (c) orientation mode, (d) social value patterns, and (e) intellectual mode. A brief description of each follows:

1. Verbal communication may be described as the structure a person uses when communicating orally. The rules or patterns for this oral communication are learned by children prior to the development of their abstract intellectual abilities. The ability to learn language seems to be a universal capacity of humankind [8, p. 42].

2. Nonverbal Communication may be described as a system of facial expression, body movements and spatial arrangements that communicate meaning to others [8, p. 59].

3. Orientation Mode refers to patterns of behavior used, regardless of the presence of others, as ways of orienting oneself to the differing contexts of one's usual environment. It may be described as the way one communicates with themselves [8, p. 74]. The orientation mode may be the most complex of the described modes. This mode is influenced by the social environment but ultimately becomes the ways one becomes comfortable in their own environment when no communication takes place.

4. Social Value Patterns are based on the sets of persistent behaviors that a group expects from its members and upon which it places certain values and upholds with certain beliefs [8, p. 89].

5. Intellectual Modes are described by Longstreet as the most emotionally charged aspect of ethnicity. This mode is not intended to deal with human innate intelligence, but rather reflect the way we externalize our thoughts, how we approach a problem, what gets our full attention, what details we are most likely to recall. Intellectual modes link intellectual performance to past experiences [8, pp. 106-107].

When seeking a model to describe human development through social interaction, and especially social interaction in digital communication environments, the notion of identity often emerges. The authors wish to acknowledge that identity focuses on the individual's definition of self [3], whereas ethnicity describes an individual's place or believed inclusion within a cultural group. This inquiry focuses on the individuals as they relate to a group. 
When constructing a scale to describe those aspects of ethnicity that may be influenced by early and pervasive interaction with digital communication technologies, consideration of which aspects to investigate was a challenging task. Longstreet (1978) predicted a variety of contextual ethnicities that may be distinct ethnicities. These distinct and specialized ethnicities were described as being grounded in one or more of the identified 5 Aspects of Ethnicity.

\subsection{Digital Ethnic Profiles}

To explore the data for possible profiles related to age and gender, a series of two-way analyses of variance was conducted. Each analysis identified statistically significance differences based on age (IM: $p=.009$; SVP: $\mathrm{p}<.001 ; \mathrm{IM}: \mathrm{p}<.001)$. The results further indicated that agreement increased as the age category increased which suggests different perceptions within each domain based on age. Concerning gender, the analysis of variance results indicated statistically significance differences between male and female respondents for SVP and OM and no statistically significant differences with respect to IM. However, unlike consistency identified in the results for age, the results indicated higher SVP values among females while females had lower values concerning OM. Finally, the results indicated there was not a statistically significant interaction between age and gender for any of the domains (IM: $p=783$; SVP: $p=.380$; OM: $\mathrm{p}=.923)$. These results are illustrated in the figures below.

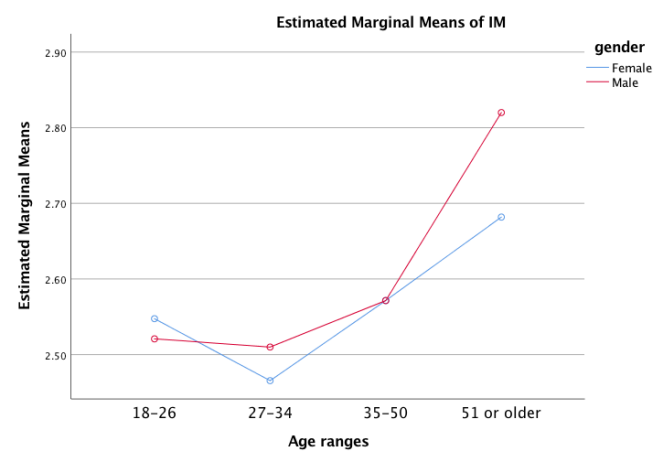

Figure 1

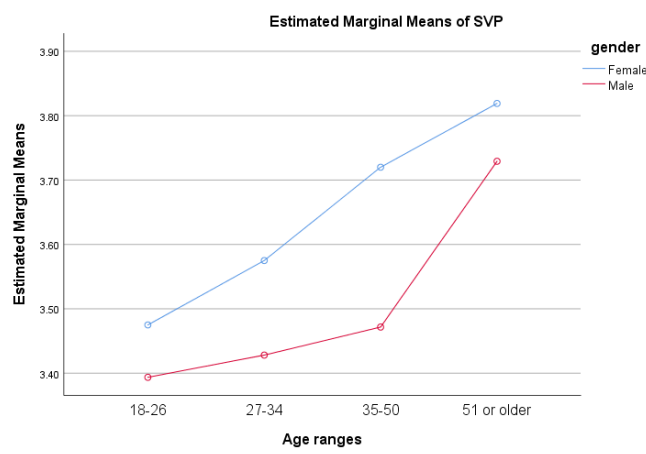

Figure 2

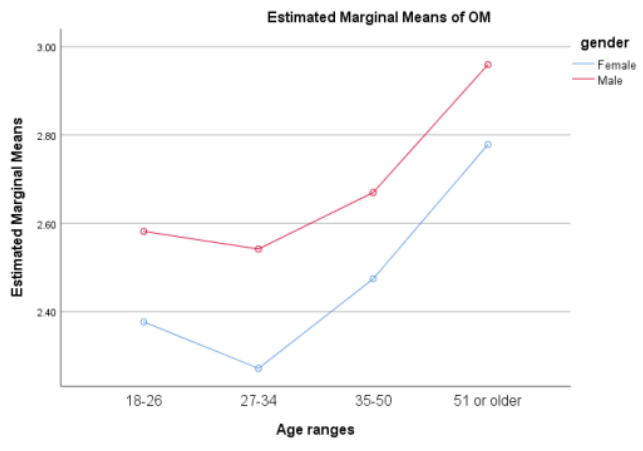

Figure 3

\subsection{Discussion of Results}

The aspects of ethnicity identified by this investigation of the specialized ethnicity termed Digital Ethnicity include (a) Orientation Mode, (b) Intellectual Mode, and (c) Social Value Patterns. As with other specialized ethnicities described by the Longstreet (1978) model, Digital Ethnicity is rooted in the combined aspects of Verbal Communication and Non-Verbal Communication that have been termed Communication Mode for 
the concept of Digital Ethnicity. The Digital Ethnicity Scale was constructed to validate the model of Digital Ethnicity (2009).

Analysis of survey data reveals significant differences by gender exist with regard to Orientation Mode and Social Value Patterns. There is little variation within Intellectual Mode with regard to gender, which may be interpreted as an indication that we are all part of the same society or national ethnic group and therefore our intellectual mode has been shaped by our surroundings - schools that share standardized planned development programs, television and other media sources with synchronized information presented in somewhat standard formats. The differences by Orientation Mode and Social Value Patterns may reflect the individual in relationship to the group and reveal relationships to 1) personal preferences and how we comfort ourselves (orientation mode) and 2) those values held as a result of our relationship to our surroundings (social value patterns).

Females returned higher means for Social Value Patterns, which indicates they have stronger agreement with the statements, which reflect stronger ties to the societal norms reflected by the survey. For example, posting private information is not acceptable, downloading music without paying for it is not acceptable, etc. Males have stronger agreement with orientation mode items, which indicates more set patterns of behavior and less flexibility for changes in preferred orientations. Because there are apparent differences and they swap for SVP and OM, it gives evidence that there are different profiles based on the three areas for male and female.

With regard to differences by age - the patterns are consistent with each age group returning similar results across the 3 identified aspects of Intellectual Mode, Orientation Mode and Social Value Patterns. This bodes well for development of Digital Ethnic Profiles. The largest difference by age occurs with those less than 50 years old and those older than 50 years, with the 3 age ranges of 18-26, 27-34 and 35-50 somewhat combined with less variability to each other and more variability with those over 50 years of age. This tracks previous research (Adams, 2004) that suggested a difference in ways of knowing may exist between those born before or after 1970 .

\section{CONCLUSION}

The pervasive use of Social Media coupled with the current lack of guidelines or policy to ensure the ethical and truthful dissemination of information through these digital Social Media communication platforms underpin the central need for utilizing the identified aspects of Digital Ethnicity model as a tool describe phenomena to guide our futures. The development of Digital Ethnic Profiles provide guidance for understanding different mindsets held by different individuals as participation in the emerging global society increases.

\section{REFERENCES}

Adams, N., DeVaney, T., \& Longstreet, W., Investigating aspects of an emerging digital ethnicity: Development of the Digital Ethnicity Scale (DES). Computers in Human Behavior, 26 (2010) 1822-1830.

Adams, N., Digital Intelligence Fostered by Technology. Journal of Technology Studies, (Spring 2004) 93-98.

Aiken, M., (2017). The Cyber Effect. New York: Spiegel \& Grau

Erikson, E. (1968). Identity: Youth and crisis. New York, NY: W. W. Norton.

Fairlie, R.W. Do Boys and Girls Use Computers Differently, and Does It Contribute to Why Boys Do Worse in School than Girls? Discussion Paper No. 9302 August 2015 IZA DP No. 9302

Kay,R.H. (2008). Exploring Gender Differences in Computer-Related Behaviour: Past, Present, and Future. 10.4018/978-1-59904-774-4.ch002.

Longstreet, W. S. (1978). Aspects of ethnicity. New York, NY: Teachers College Press.

Pew Research (2019)(https://www.pewinternet.org/chart/social-media-use-by-gender/).

Shearer, E., \& Gottfried, J. (2017). News Use Across Social Media Platforms 2017. Pew Research Center. Retrieved from http://www.journalism.org/2017/09/07/news-use-across-social-media-platforms-2017/

Statista (https:/www.statista.com/statistics/266587/percentage-of-internet-users-by-age-groups-in-the-us/) 